\title{
Saving \$I million (and counting) on blood acquisition
}

\section{Opinion}

In December 2016, the US Agency for Healthcare Research and Quality (AHRQ) posted a new statistical brief on. ${ }^{1}$ The AHRQ reported that the number of adult inpatient stays featuring the procedure had continued to rise, growing $85.8 \%$ from 2000 through 2013. And the rate of increase was climbing substantially faster than that of inpatient stays-not good news for patient safety. Thanks to a collaborative approach that builds on its strengths, Geisinger Health System in Pennsylvania is ahead of the game. In 2013, a paper on blood product utilization published by the health care performance consortium Premier, Inc., gave Amanda E. Haynes, DO, FCAP, (formerly Amanda E. Wehler) what she needed to put Geisinger's own performance in context, create a sense of urgency, and enable a pivotal shift in attitudes. People got it. And the resulting system-wide effort saved more than \$1 million in blood acquisition costs in FY2015.

Premier had looked at lower blood product utilization coupled with better-than-expected patient outcomes to benchmark one in four (7.4million) patient discharges at 464 member hospitals. They'd also used the percentage of annual discharges reflecting inpatient transfusion as a quality measure. Geisinger had shown up in the bottom docile for blood utilization management, Dr. Haynes said, and "that one piece of data and peer comparison were enough to get the attention of the administration and the other physicians." Dr. Haynes had already been thinking about a paper in Transfusion ${ }^{2}$ describing an activity-based costing ("ABC") model for RBC transfusion that accounted for process steps, staff, and consumables. Incorporating indirect expenses yielded $\mathrm{RBC}$ unit costs that were 3.2- to 4.8 fold higher than blood product acquisition costs alone.

That nailed it. Dr. Haynes had three goals at the outset:

i. Look at transfusion rates by service line or individual physician so that improvement goals could be focused and tailored.

ii. Begin using evidence-based transfusion guidelines reflecting recent research showing that using a lower hemoglobin threshold for transfusion did not compromise patient safety; and

iii. Embed those guidelines in the electronic health record as part of the computerized physician order entry system to encourage compliance and track systemwide progress in that direction. In the end, they were three for three.

Dr. Haynes's data-driven arguments generated support from clinicians, health information management specialists, and administrators alike. She was a physician on a mission and by July 2013, Geisinger had a diverse, well-integrated team and a patient blood management project that used evidence-based transfusion guidelines. Geisinger's presurgical planning began to integrate principles designed to prevent anemia. Blood management tools (for example, use of tranexamic acid in orthopedic hip and knee surgery, laboratoryguided transfusion algorithms for cardiac surgical bleeding, and anemia management interventions before elective surgery could be scheduled) were embedded into bundled episodes of care.

In July of 2015, Dr. Haynes's team was able to report 23\% and 27\%

\author{
Volume 4 Issue 5 - 2017
}

\begin{abstract}
Amanda E Haynes
Department of Clinical pathology and Anatomic pathology, Pennsylvania Osteopathic Medical Association, USA
\end{abstract}

Correspondence: Amanda E Haynes, Department of Clinical pathology and Anatomic pathology, Pennsylvania Osteopathic Medical Association, 100 North Academy Avenue Danville, PA |7822-1930I 800695 649I, USA, Email aehaynes@geisinger.edu

Received: May 5 2017 | Published: May II, 2017

drops in packed red blood cell utilization at Geisinger's two largest campuses. That translated to a $\$ 1.2$ million drop in blood acquisition costs across the health system in FY2015 compared to the year before. That very good news was by then old news to Dr. Haynes, who had zeroed in on results from the third campus, where transfusion rates had not budged. Good job; let's move on and figure this out. If that's how change agents think, fast is how change agents move.

Dr. Haynes, who joined the medical staff at Pennsylvanian's Geisinger Health System in 2010 right out of fellowship, had been named medical director for transfusion medicine and stem cell collections a few months later. She had acquired another title in July 2011:medical director of stem cell processing. Today, she is also vice chair of the Geisinger Health System Patient Blood Management Committee and a physician leader for their strategic plan. What she learned as a CAP volunteer has fostered her career, Dr. Haynes says. As the CAP's Residents Forum chair, she'd had a seat on its Board of Governors a good place to learn how to build a strategy and use data to persuade. Today, she is a member of the CAP's Council on Scientific Affairs and Nominating Committee.

Metrics will drive movement in population health, Dr. Haynes says, by providing the foundation that makes the most difference for the most patients. The goal is to reach a point where only hemorrhaging patients will receive an RBC transfusion. Until then, she will do monthly reports to the service line leaders that track physician performance against the transfusion guidelines. And her team will continue to recruit medical staff champions at each location and encourage nurses to advocate within their clinical teams for the patient safety benefits that accrue with adherence.

The Geisinger group did not target platelet and plasma use during the project period, yet utilization rates for both improved as well. It seems there's more than one way to build on success. "We've really just scratched the surface," Dr. Haynes says. "What can we do to further impact the utilization of plasma or of platelets? Platelets are almost three times the cost of red cells. We haven't even really started."And besides, she's still studying the data from their third campus. Post-project data mining had suggested a problem with the benchmarking. That could be all it was, but still, she wonders. Data that are off the charts should jump off the charts. Why didn't the 
outliers prompt immediate questions about how the model had been applied at that campus?

"If you're going to do change management, you can't just apply one standard process across the health system," Dr. Haynes says. "You have to understand the culture of each and every campus, what the differences are, and what different approaches can be used to impact change in those different cultures."

\section{Acknowledgements}

None.

\section{Conflict of interest}

The author declares no conflict of interest.

\section{References}

1. Shander A, Hofmann A, Ozawa S, et al. Activity-based costs of blood transfusions in surgical patients at four hospitals. Transfusion. 2010;50(4):753-765.

2. Kamille AW, Marguerite LB, Brian JM, et al. Trends in Hospitalizations Witha Red Blood Cell Transfusion, 2000-2013:statistical Brief \#215. USA: AHRQ; 2016. 